\title{
Seasonal Prevalence and Host Preference of Some Medically Important Aedes Species of Doon Valley, India
}

\author{
Ritwik Mondal', N Pemola Devi' ${ }^{2}$, Sajal Bhattacharya ${ }^{3}$ \\ ${ }^{1}$ Department of Zoology, University of North Bengal, West Bengal, India. \\ ${ }^{2}$ Department of Zoology, D.B.S. (P.G.) College, Dehradun, Uttarakhand, India. \\ ${ }^{3}$ Department of Zoology, Asutosh College (University of Calcutta), Kolkata, West Bengal, India. \\ DOI: https://doi.org/10.24321/0019.5138.202144
}

I $\mathbf{N}$ F $\mathbf{O}$

\section{Corresponding Author:}

Ritwik Mondal, Department of Zoology, University

of North Bengal, West Bengal, India.

E-mail Id:

ritwikm.zoology@nbu.ac.in

Orcid Id:

https://orcid.org/0000-0003-3655-6767

How to cite this article:

Mondal R, Pemola Devi N, Bhattacharya S. Seasonal Prevalence and Host Preference of Some Medically Important Aedes Species of Doon Valley, India. J Commun Dis. 2021;53(3):96-103.

Date of Submission: 2021-06-25

Date of Acceptance: 2021-08-07
$\begin{array}{lllllllllll}\mathbf{A} & \mathbf{B} & \mathbf{S} & \mathbf{T} & \mathbf{R} & \mathbf{A} & \mathbf{C} & \mathbf{T}\end{array}$

In the recent past, several outbreaks of mosquito-borne diseases in Dehradun city make it necessary for a comprehensive understanding of man-vector contacts, disease transmission and determination of appropriate resting sites for adult mosquitoes. The study was conducted within the periphery of Dehradun city in Doon valley, Uttarakhand state, India consisting of eight (08) locations namely Sahaspur, Premnagar, Raipur, Karanpur, Sahastradhara, Dudhli, Doiwala and Rani Pokhri with the objective to analyze and assess the seasonal prevalence and host choice of the mosquitoes with special reference to Aedes species. Among the eight locations of the current study, Raipur registered the highest mosquito abundance $(17 \%)$ trailed by Sahaspur $(16 \%)$ and Karanpur (15\%). A low abundance of mosquitoes was registered conjointly from Doiwala and Rani Pokhri areas ( $9 \%$ from each area). In these areas, the profile plots of the 2-way ANOVA displayed the highest variation for the data collected from human habitations followed by bovine sheds, whereas the lowest recorded variation was from the poultry. With regards to seasonal prevalence, the highest mosquito abundance was registered during the monsoon followed by the postmonsoon. In provender analysis, a total of 1912 blood meals were collected for antibody test among which 1851 were found positive, with the highest reaction with human antisera $(57.75 \%)$, followed by bovine antisera (21.34\%) and pigs antisera (4.97\%). Ae. aegypti had the highest Anthropophilic Index (A.I.) with $68.78 \%$, followed by Ae. albopictus (64.89\%) and Ae. vittatus (55.55\%). However, Human Blood Predominance (H.B.P.) and Pure Human Blood Pervasiveness (P.H.B.P.) were found highest for Ae. albopictus with values 0.43 and 0.44 respectively. The results also show the seasonal prevalence and feeding habits of these vectors. This study would be helpful in formulating season-wise strategies for the control of Aedes vector mosquitoes in different eco-epidemiological situations.

Keywords: Aedes Species, Double Immunodiffusion, Blood Meal Analysis, Host Preference, Seasonal Prevalence 


\section{Introduction}

Adult mosquitoes persist within the fringes of human dwellings. However, it is the female mosquitoes that mostly enter the human habitations to get blood meals. ${ }^{1}$ The vector capacities of mosquitoes rely upon numerous parameters like biting frequency, dissemination ability, and native profusion; however, the foremost important facet behind the vector capacity lies in host preferences and supported blood meal supply. ${ }^{2}$ Mosquitoes belonging to genus Aedes perpetually depend on over one host for one gonotrophic cycle, primarily showing their manlanding activity throughout the hours of daylight. ${ }^{3}$ Several researchers reported on the impalpable resting habits of Aedes species..$^{4-7}$ The double immunodiffusion technique has been widely favoured by researchers to determine dipteron blood meal. ${ }^{8}$ It is advantageous for the opacity, the murkiness of reactants and purging of the floating debris as these parts get sieved through the gel. Besides that, the technique offers prompt leads to determine the host preferences of mosquitoes in a given neighbourhood. .,10 $^{9}$ Mosquito provender identification has been further in practice to analyse the feeding behaviours of mosquitoes. ${ }^{11-17}$

Given the reportable state of affairs of the several outbreaks of mosquito-borne diseases in Dehradun in the recent past; there is a standing purpose for the evaluation of each manvector contact, disease transmission and determination of appropriate resting sites for adult mosquitoes. To achieve that goal analysis of multiple blood-feeding behaviours of mosquitoes on different hosts have been recognized as an important step in determining their potential host range and seasonal preferences. ${ }^{4,10}$ This study preponderantly focuses on the analysis and assessment of the seasonal prevalence and host choice of mosquitoes, with special reference to the provender analysis of Aedes species, in order to formulate comprehensive management strategies to prevent any potential outbreaks of mosquito-borne diseases.

\section{Methodology}

\section{Study Area and Time Period}

The study was conducted within the boundary of Dehradun town in Doon valley (latitude $30^{\circ} 19^{\prime} \mathrm{N}, 7^{\circ} 04^{\prime} \mathrm{E}$, longitude $77^{\circ} 35^{\prime} \mathrm{E}$ to $78^{\circ} 20^{\prime} \mathrm{E}$ ) of district Dehradun (Uttarakhand) consisting of eight locations viz. Sahaspur, Premnagar, Raipur, Karanpur, Sahastradhara, Dudhli, Doiwala and Rani Pokhri. The study time was alienated into four distinct seasons from Sep-14 to Aug-15 viz. Post-Monsoon (Sep-Nov), Winter (DecFeb), Summer (Mar-May) and Monsoon (Jun-Aug) (Figure 1).

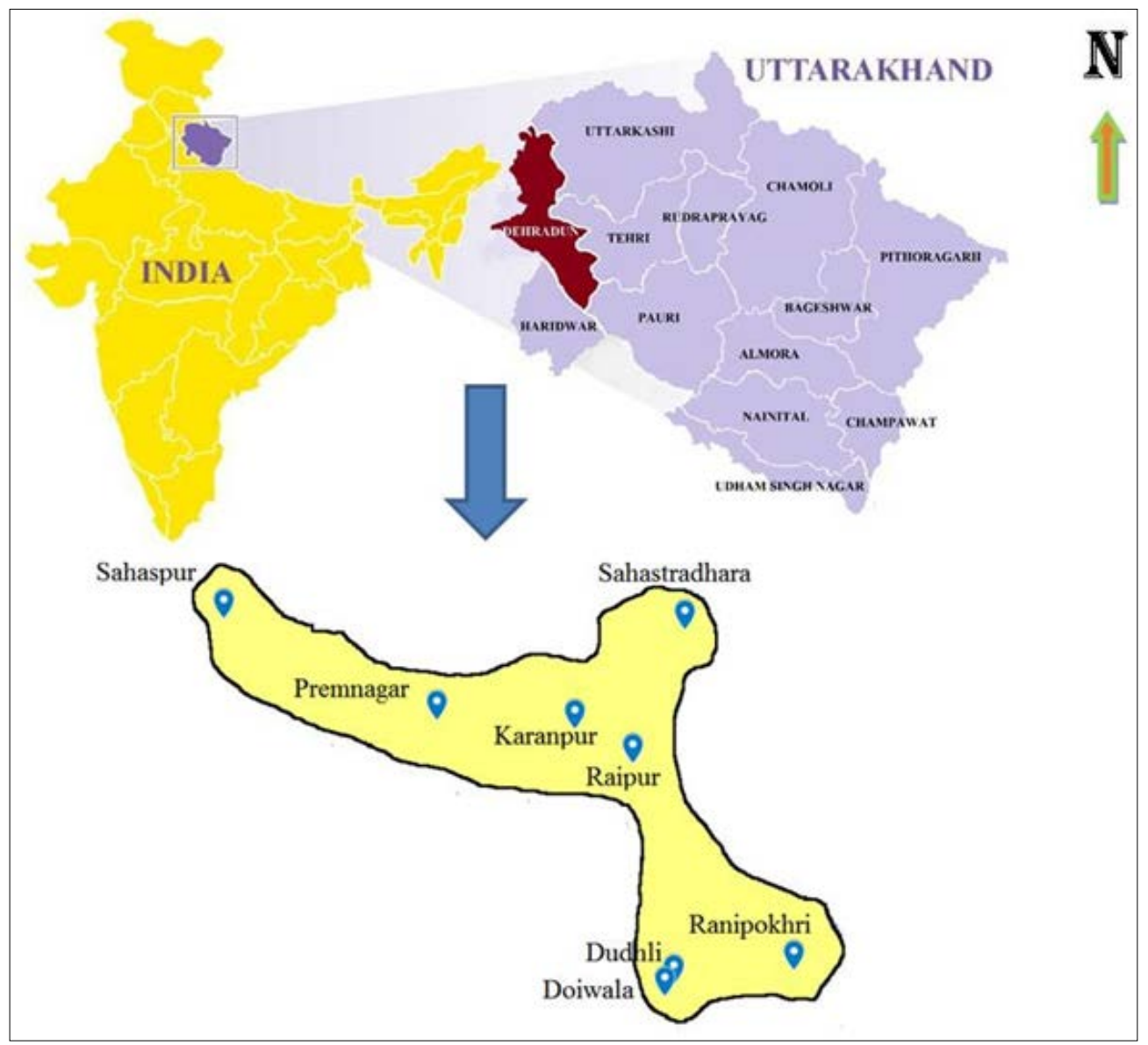

Figure I.Study Sites on the Periphery of Dehradun District 


\section{Mosquito Surveillance}

A door to door survey was performed for the detection of indoor-resting mosquitoes between 06:00 and 08:00 hrs within the morning and between 16:00 and 18:00 hrs in the evening for six min from every habitation weekly, following hand collection methodology and mouth aspirators. ${ }^{18}$ Permissions were sought-after from inhabitants to perform indoor-resting mosquito collections for the study. The habitations of the locations were chiefly categorized into four distinct habitations viz. human habitations, cattle sheds, pig farm and poultry.

\section{Blood Meal Analysis}

Blood meal of mosquito was detected by antibody checking by the agar-gel diffusion technique involving the diffusion of antigen (extract proteins contained in blood from the abdomen of mosquito) and antibody (specific to human, cattle, pig and fowl collected from the Institute of Serology, Kolkata, India) through agar gel so that precipitin reaction leaves a detectable precipitate band according to the outline of Ouchterlony O, Nilson LA. ${ }^{19}$

\section{Blood Meal Estimation}

The estimation of blood meal parameters was performed with slight alteration following the protocols developed by Collins RT et al. ${ }^{20}$

- The Anthropophilic Index (A.I.) is the proportion of antibody from one Aedes species that is positive for human blood. The A.I. typically combines information from many different biotopes and thus is also powerfully biased towards one host or another.

- The Human Blood Predominance (H.B.P.) refers to the proportion of the full precipitin containing human blood (both mixed and pure) from all species combined, which are comprised of selected species.

- The Pure Human Blood Pervasiveness (P.H.B.P.) refers to the precipitin that contains only pure (unmixed) human blood.

\section{Statistical Analysis}

A two-way ANOVA check was performed to determine the impact of seasons and habitations over the variation of mosquitoes with a $p$-value $\leq 0.05$ was considered statistically important performed in SPSS (version 17.0). ${ }^{21}$ To determine the fluctuation among feeding behaviour of Aedes species a two-tailed Z test was performed in XLSTAT (Version 7.5.2) wherever a $p$-value $\leq 0.05$ was considered statistically significant. $^{21}$

\section{Results}

Among the 08 locations in the current study, the Raipur area had the highest mosquito abundance (17\%) trailed by Sahaspur (16\%) and Karanpur (15\%) whereas the lowest abundance was registered collectively from Doiwala and Rani Pokhri (with 9\% each) (Figure 2). Aedes (13.22\%) and Armigeres (0.17\%) mosquitoes were found most prevalent in human habitations throughout monsoon (Jun-Aug) among all the seasons. However, the abundance of Anopheles and Culex mosquitoes were found highest during the Post-Monsoon (Sep-Nov) among all seasons from human habitats. The abundance of Anopheles and Culex mosquitoes were $7.65 \%$ and $8.04 \%$ respectively. The abundance of all the 04 genera of mosquitoes studied recorded lowest during the Winter (Dec-Feb) from poultry (Figure 3). The two-way ANOVA showed that the abundance of mosquitoes considerably varied in keeping with completely different habitats and also as different seasons $(p \leq 0.05)$.

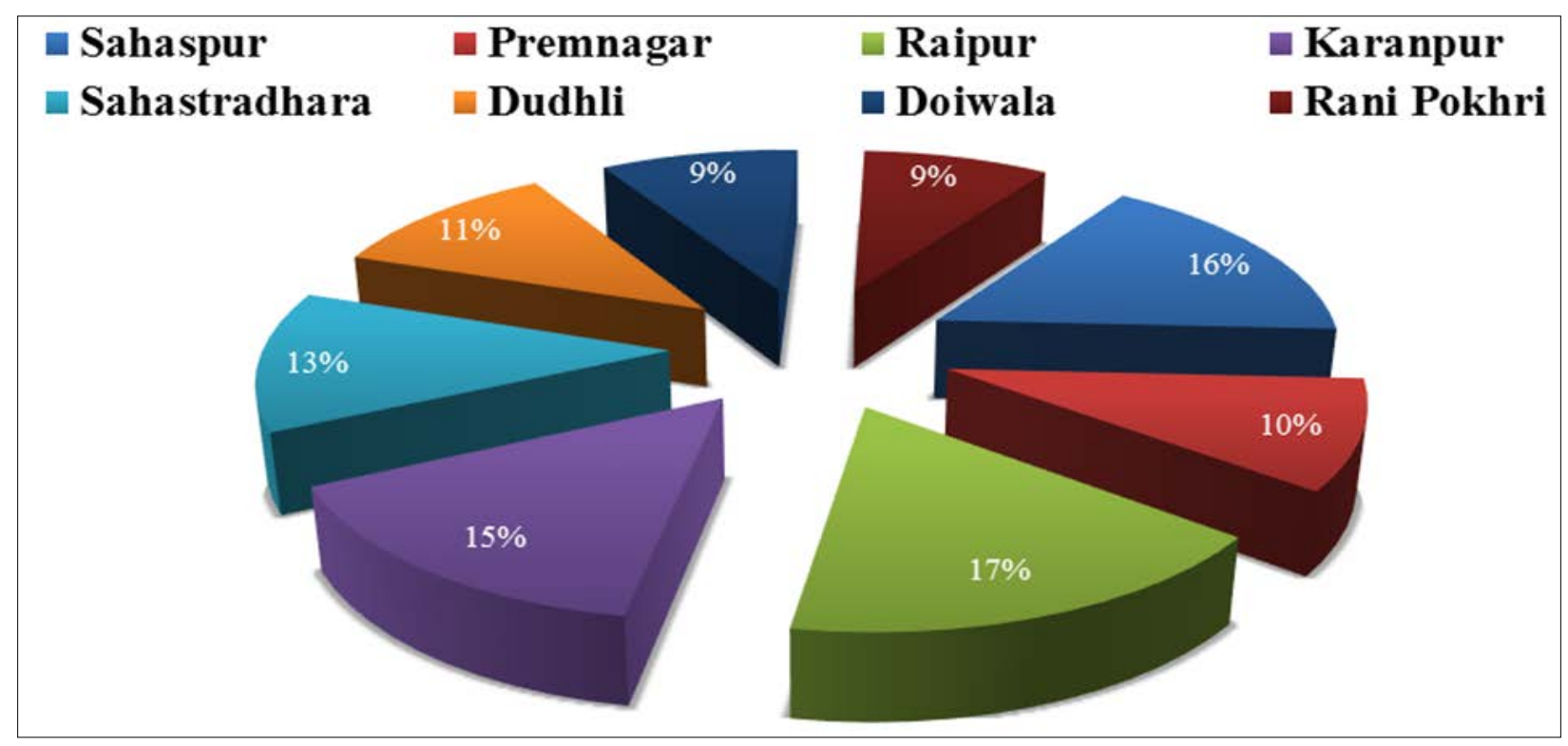

Figure 2.Abundance of the Mosquito Genera Location Wise 
Figure 4, depicts the profile plots of the 2-way analysis of variance estimating the means that of the Aedes species, showing the variation is highest for human habitations followed by bovine sheds, whereas recorded lowest within the poultry. Among Aedes mosquitoes, season-wise parameters monsoon had the highest variation followed by post-monsoon, whereas the lowest variation among the four habitats was recorded in summer.

Statistical analysis of provender by Z-test disclosed that vital variation $(p \leq 0.05)$ was found among the preference of Aedes species for the total antibody of human blood is $Z=16.07$, among that vital variation for the pure human blood, is $Z=26.919$ and mixed-blood is $Z=2.848$. In infeed analysis, a total of 1912 blood meals were checked for antibody test, and among them, 1851 samples were found positive. The best reaction was found with human antisera 1069 (57.75\%), followed by bovine antisera 395 (21.34\%) and the lowest from poultry antisera 92 (4.97\%). Mixed blood accounted for 127 positive blood meals, consisting of $6.86 \%$ of the total positive samples (Table 1 ).

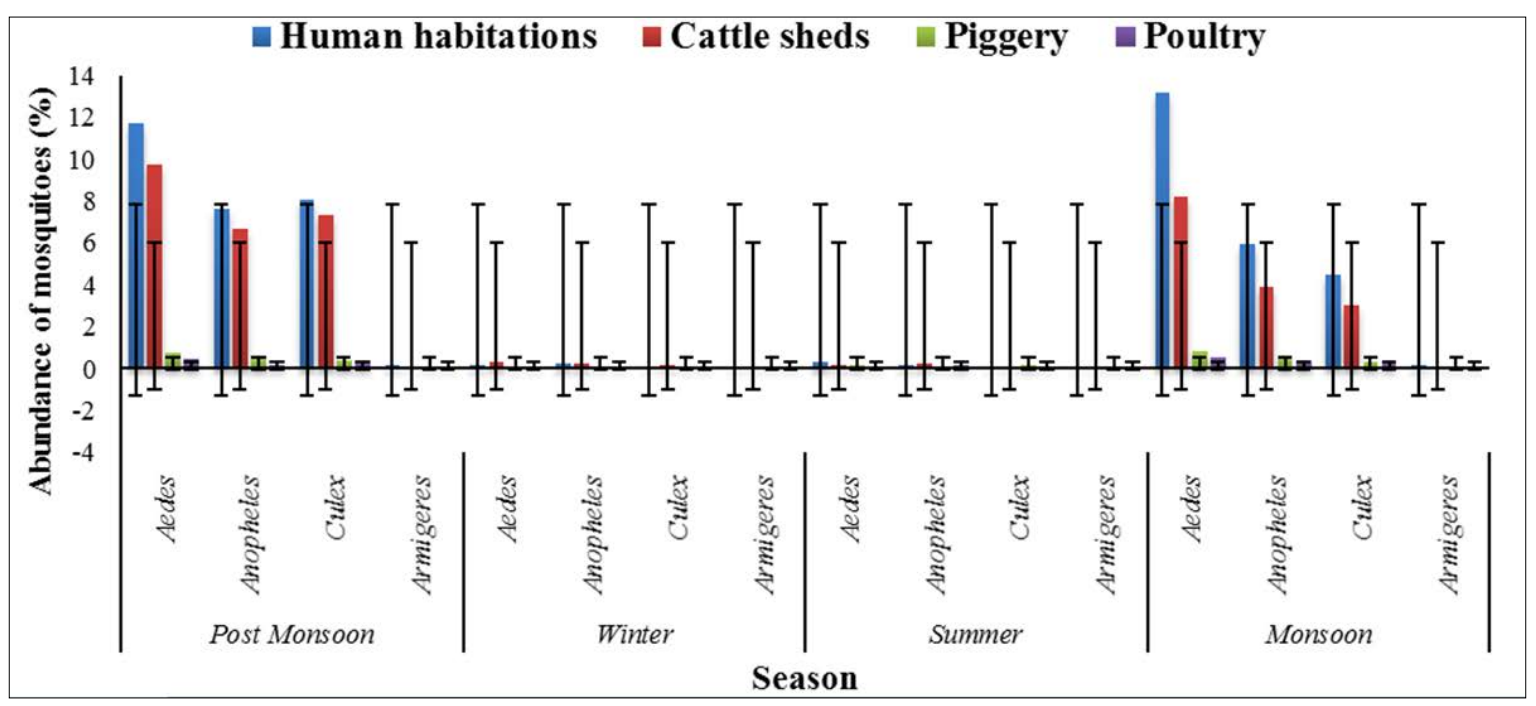

Figure 3.Mosquito Abundance (\%) in Different Seasons at 04 Categorized Distinct Habitations

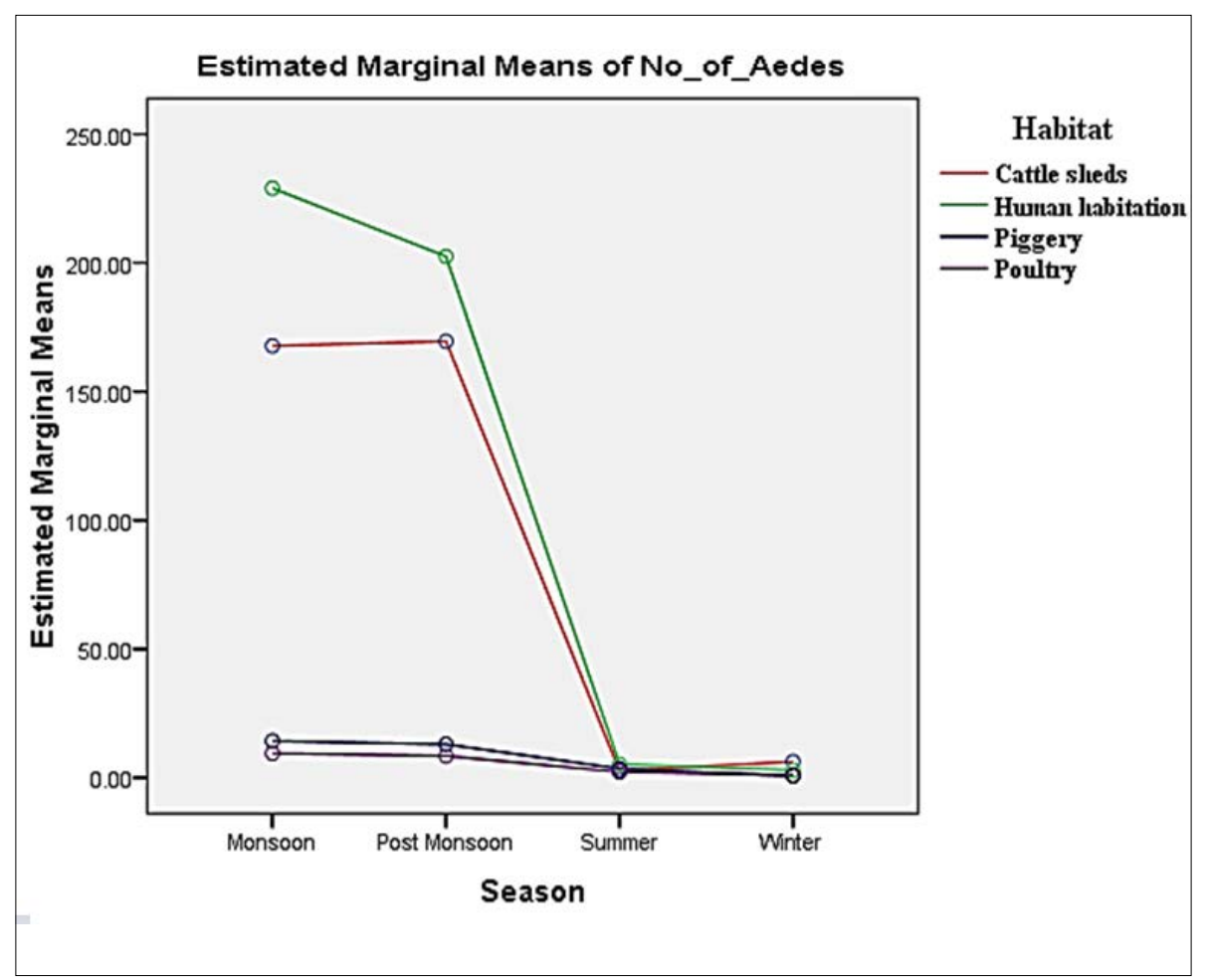

Figure 4.Profile Plot of No. of Aedes Species in 04 Distinct Habitats during Different Seasons (from Sep- 4 to Aug- 15) around the Periphery of Dehradun City 
Table I.Blood Meal Analysis of Aedes Species from Sep- 14 to Aug- 5

\begin{tabular}{|c|c|c|c|c|c|c|c|c|}
\hline \multirow{2}{*}{ Seasons } & \multirow{2}{*}{$\begin{array}{l}\text { Aedes } \\
\text { species }\end{array}$} & \multirow{2}{*}{$\begin{array}{l}\text { Blood meal } \\
\text { tested }\end{array}$} & \multirow{2}{*}{$\begin{array}{c}\text { Blood } \\
\text { meal +ve }\end{array}$} & \multicolumn{5}{|c|}{ Number and \% positive for respective antisera } \\
\hline & & & & Human & Bovine & Pig & Fowl & Mixed \\
\hline \multirow{3}{*}{$\begin{array}{c}\text { Post } \\
\text { monsoon }\end{array}$} & Ae. aegypti & 312 & 303 & $\begin{array}{c}192 \\
(63.37 \%)\end{array}$ & $\begin{array}{c}55 \\
(18.15 \%) \\
\end{array}$ & $\begin{array}{c}14 \\
(4.62 \%) \\
\end{array}$ & $\begin{array}{c}7 \\
(2.31 \%) \\
\end{array}$ & $\begin{array}{c}35 \\
(11.55 \%) \\
\end{array}$ \\
\hline & $\begin{array}{c}\text { Ae. } \\
\text { albopictus }\end{array}$ & 352 & 343 & $\begin{array}{c}206 \\
(60.06 \%) \\
\end{array}$ & $\begin{array}{c}73 \\
(21.28 \%) \\
\end{array}$ & $\begin{array}{c}29 \\
(8.45 \%) \\
\end{array}$ & $\begin{array}{c}18 \\
(5.25 \%) \\
\end{array}$ & $\begin{array}{c}17 \\
(4.96 \%) \\
\end{array}$ \\
\hline & Ae. vittatus & 187 & 179 & $\begin{array}{c}91 \\
(50.84 \%) \\
\end{array}$ & $\begin{array}{c}47 \\
(26.26 \%) \\
\end{array}$ & $\begin{array}{c}22 \\
(12.29 \%)\end{array}$ & $\begin{array}{c}16 \\
(8.94 \%) \\
\end{array}$ & $\begin{array}{c}3 \\
(1.68 \%) \\
\end{array}$ \\
\hline \multirow{3}{*}{ Winter } & Ae. aegypti & 12 & 8 & $\begin{array}{c}4 \\
(50.0 \%) \\
\end{array}$ & $\begin{array}{c}2 \\
(25.0 \%) \\
\end{array}$ & $\begin{array}{c}1 \\
(12.5 \%) \\
\end{array}$ & 0 & $\begin{array}{c}1 \\
(12.5 \%) \\
\end{array}$ \\
\hline & $\begin{array}{c}\text { Ae. } \\
\text { albopictus }\end{array}$ & 8 & 6 & $\begin{array}{c}2 \\
(33.33 \%)\end{array}$ & $\begin{array}{c}3 \\
(50.0 \%)\end{array}$ & 0 & $\begin{array}{c}1 \\
(16.67 \%)\end{array}$ & 0 \\
\hline & Ae. vittatus & 7 & 5 & $\begin{array}{c}2 \\
(40.0 \%)\end{array}$ & $\begin{array}{c}1 \\
(20.0 \%)\end{array}$ & $\begin{array}{c}1 \\
(20.0 \%)\end{array}$ & 0 & $\begin{array}{c}1 \\
(20.0 \%)\end{array}$ \\
\hline \multirow{3}{*}{ Summer } & Ae. aegypti & 17 & 10 & $\begin{array}{c}3 \\
(30.0 \%) \\
\end{array}$ & $\begin{array}{c}2 \\
(20.0 \%) \\
\end{array}$ & $\begin{array}{c}2 \\
(20.0 \%) \\
\end{array}$ & $\begin{array}{c}1 \\
(10.0 \%) \\
\end{array}$ & $\begin{array}{c}2 \\
(20.0 \%) \\
\end{array}$ \\
\hline & $\begin{array}{c}\text { Ae. } \\
\text { albopictus }\end{array}$ & 21 & 19 & $\begin{array}{c}10 \\
(52.63 \%)\end{array}$ & $\begin{array}{c}5 \\
(26.32 \%) \\
\end{array}$ & 0 & $\begin{array}{c}2 \\
(10.53 \%)\end{array}$ & $\begin{array}{c}2 \\
(10.53 \%) \\
\end{array}$ \\
\hline & Ae. vittatus & 11 & 8 & $\begin{array}{c}3 \\
(37.50 \%) \\
\end{array}$ & $\begin{array}{c}2 \\
(25.0 \%) \\
\end{array}$ & $\begin{array}{c}1 \\
(12.5 \%) \\
\end{array}$ & $\begin{array}{c}1 \\
(12.5 \%) \\
\end{array}$ & $\begin{array}{c}1 \\
(12.5 \%) \\
\end{array}$ \\
\hline \multirow{3}{*}{ Monsoon } & Ae. aegypti & 394 & 390 & $\begin{array}{c}211 \\
(54.10 \%)\end{array}$ & $\begin{array}{c}81 \\
(20.77 \%) \\
\end{array}$ & $\begin{array}{c}33 \\
(8.46 \%) \\
\end{array}$ & $\begin{array}{c}24 \\
(6.15 \%) \\
\end{array}$ & $\begin{array}{c}41 \\
(10.51 \%) \\
\end{array}$ \\
\hline & $\begin{array}{c}\text { Ae. } \\
\text { albopictus }\end{array}$ & 429 & 421 & $\begin{array}{c}256 \\
(60.81 \%) \\
\end{array}$ & $\begin{array}{c}83 \\
(19.71 \%) \\
\end{array}$ & $\begin{array}{c}46 \\
(10.93 \%) \\
\end{array}$ & $\begin{array}{c}17 \\
(4.04 \%) \\
\end{array}$ & $\begin{array}{c}19 \\
(4.51 \%)\end{array}$ \\
\hline & Ae. vittatus & 162 & 159 & $\begin{array}{c}89 \\
(55.97 \%) \\
\end{array}$ & $\begin{array}{c}41 \\
(25.79 \%) \\
\end{array}$ & $\begin{array}{c}19 \\
(11.95 \%)\end{array}$ & $\begin{array}{c}5 \\
(3.14 \%) \\
\end{array}$ & $\begin{array}{c}5 \\
(3.14 \%)\end{array}$ \\
\hline Total & & 1912 & 1851 & $\begin{array}{c}1069 \\
(57.75 \%)\end{array}$ & $\begin{array}{c}395 \\
(21.34 \%)\end{array}$ & $\begin{array}{c}168 \\
(9.08 \%)\end{array}$ & $\begin{array}{c}92 \\
(4.97 \%)\end{array}$ & $\begin{array}{c}127 \\
(6.86 \%)\end{array}$ \\
\hline
\end{tabular}

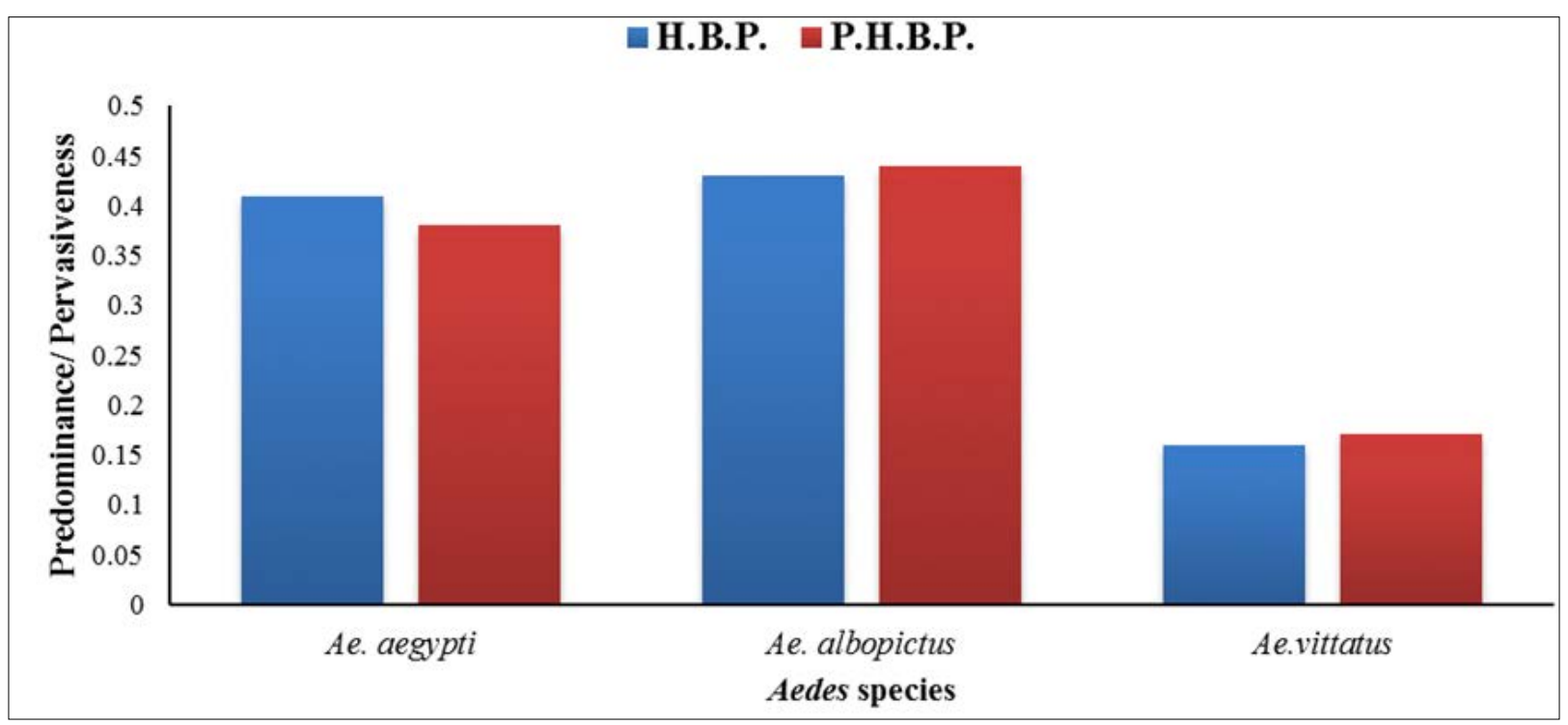

Figure 5.Comparison Showing between Human Blood Predominance (H.B.P.) and Pure Human Blood Pervasiveness (P.H.B.P.) among 03 Species of Aedes during the Study Period 


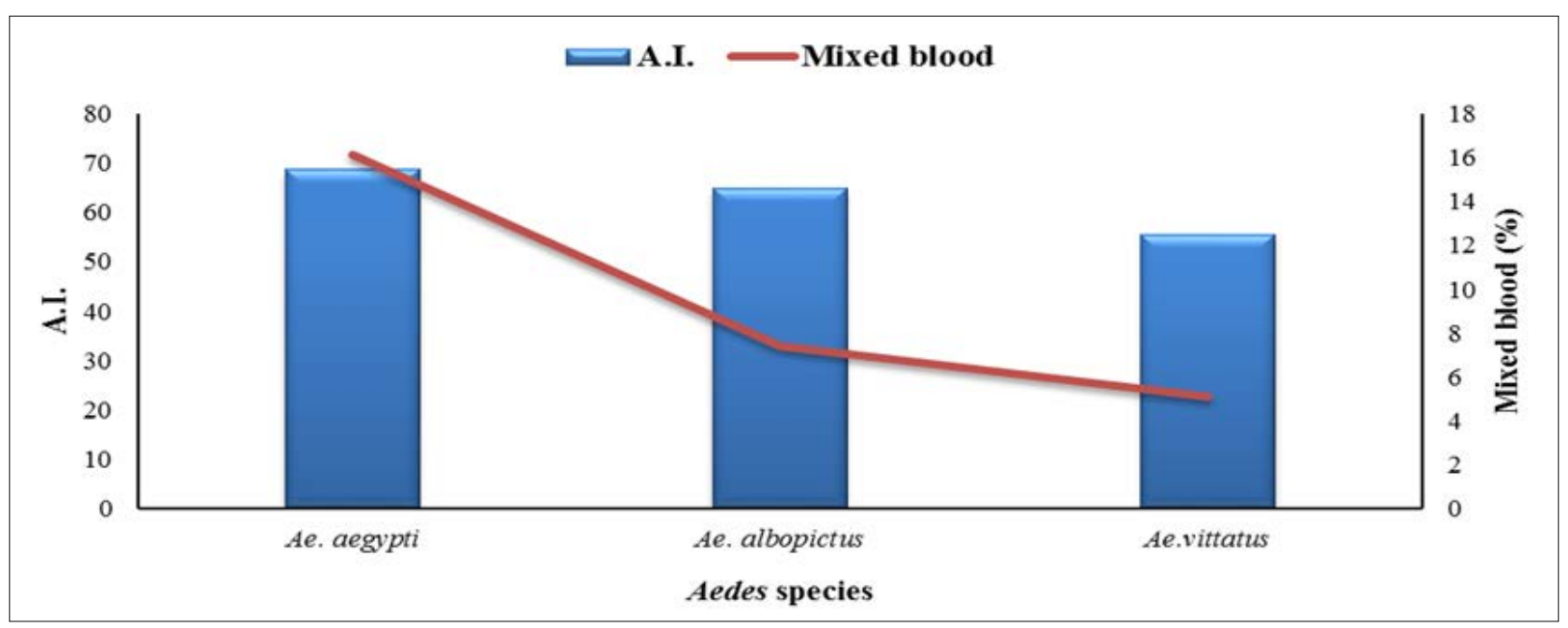

Figure 6.Column-line Diagram Depicts the Anthropophilic Index (A.I.) and Mixedblood Composition among 03 Species of Aedes

Figure 5 depicts the comparison between Human Blood Predominance (H.B.P.) and Pure Human Blood Pervasiveness (P.H.B.P.) among the reported 03 Aedes species. Human Blood Predominance (H.B.P.) and Pure Human Blood Pervasiveness (P.H.B.P.) were found highest for Ae. albopictus with 0.43 and 0.44 values and lowest for $A e$. vittatus with the worth of 0.16 and 0.17 respectively (Figure 5). Ae. aegypti recorded highest for A.I. with (68.78\%), followed by Ae. albopictus (64.89\%) and Ae. vittatus $(55.55 \%)$. The constant hierarchal pattern was seen in the mixed-blood analysis viz. Ae. aegypti (16.16\%) $>A e$. albopictus (7.42\%) > Ae. vittatus (5.13\%). Figure 6 portrays a column-based diagram of Anthropophilic Index (A.I.) and mixed-blood composition among 03 species of Aedes.

\section{Discussion}

Earlier, it was explicit that Ae. aegypti is strictly domiciliary, preferring less vegetation, biting inside and primarily found indoors, whereas Ae. albopictus and Ae. vittatus was found outdoors and breed in varieties of natural containers. ${ }^{15,16,22}$ Being contradictory, the results of this study shows all the studied species of Aedes were found within the human habitations and cattle sheds considerably. However, in a facet of seasonal prevalence, there are similarities with the studies conducted by a group of researchers in Selangor, Malaysia ${ }^{4}$, with the highest abundance of Aedes recorded throughout monsoon followed by postmonsoon. A decent range of mosquitoes found in human habitations in conjunction with comparatively less number in kine sheds, farm and poultry, indicating that preferring resting sites could be related to their blood-feeding habits (anthropophagic or zoophagic, etc.). ${ }^{11,17}$ The abundance of mosquitoes found within the human habitations in the present study is considerably higher than that of the results of Azmi SA et al., ${ }^{17}$ which is suggestive that appropriate and varied breeding sites favour the mosquitoes to make up such high-density populations within the human habitations.

Mixed blood as provender ensuing from two or more feeds may not be necessarily in sequences of feeding, and some blood varieties might remain insufficiently digested, which may affect the origin identification of blood samples. ${ }^{7,11}$ However, the tendency of the mosquitoes to take multiple blood meals could get genetically explained. It appears more probable that the mixed feeding behaviour is either an expression of most liked feeding or is caused by interrupting feeding because of anti-mosquito actions taken by the intended host, which ultimately results in a cryptic behaviour. ${ }^{20,23}$ The results of multiple blood parameters of this study support the studies previously conducted in Chhattisgarh, however, the results vary within the genus. ${ }^{10}$ Once the female Aedes reaches a threshold level, the blood-induced-distension of the gut wall triggers a refractory period during which females do not take provenders. Also, if the blood meal initiates vitellogenesis in female mosquitoes, a second inhibition accompanies gametocyte development. ${ }^{8,14}$ It was reported from Puerto Rico that Aedes mosquitoes processed blood by pre-diuresis throughout blood-feeding and by diuresis on completion of blood-feeding, particularly while resting. ${ }^{13}$ The studies by Washino RK, Tempelis $\mathrm{CH}$ reflected the very fact on blood meal identification that mosquitoes have developed two host choice methods viz. (a) 'fixed' or 'active' and (b) 'expedient' or 'passive' by the passage of time. ${ }^{3}$ Species belonging to Aedes show a 'fixed' host preference pattern and feed primarily on mammals. ${ }^{9,24}$ This study reveals $90.48 \%$ of Aedes mosquitoes feeding on a single host, whereas $6.64 \%$ counted for multiple hosts feeding for a single gonotrophic cycle. The results indicate that, as humans are excitable hosts before a mosquito becomes engorged several interrupted half meals might occur from humans. ${ }^{24,25}$ 
One demerit of the provender identification techniques is a scarce sensitivity to reveal mixed feedings. Nevertheless, every sample of mixed blood meal supports the very fact that one or a lot of feeding taken by mosquitoes. It looks plausible that the propensity for a species to change pronto from one host to another may dilute its vector potential. ${ }^{20}$ Thus regardless of wherever the mosquitoes got captured, it is essential to analyze their blood meals to establish a rudimentary understanding of their actual feeding behaviour.

\section{Conclusion}

Aedes mosquitoes are vectors of several important diseases such as dengue, chikungunya, Zika and yellow fever. Among these diseases first three are endemic to India. Recurrent epidemics of dengue and chikungunya in different parts of India are causing concerns to the public health authorities. Ae. aegypti and Ae. albopictus are recognized vectors for these diseases. It has been delineated that $A e$. vittatus also has the potential to be the vectors for several above-mentioned diseases. The present study throws light on the preferred habitats, seasonal prevalence and feeding habits of these vectors. This study would be helpful in formulating season-wise and area wise strategies for the control of Aedes vector mosquitoes in different ecoepidemiological situations.

\section{Acknowledgements}

The first two authors are grateful to Council for Scientific and Industrial Research (CSIR), New Delhi [Ref No. 37 (1526)/12 EMR II] for financial support. Thanks are due to the Institute of Serology, Kolkata and the Ecology unit of Forest Research Institute, Dehradun.

\section{Conflict of Interest: None}

\section{References}

1. Barraud PJ, Christophers SR. On a collection of Anopheles and Culicine mosquitoes from Siam. Rec Malaria Sur India. 1931;2(2):269-89.

2. Chaves LF, Harrington LC, Keogh CL, Nguyen AM, Kitron UD. Blood feeding patterns of mosquitoes: random or structured? Front Zool. 2010 Jan 21;7:3. [PubMed] [Google Scholar]

3. Washino RK, Tempelis $\mathrm{CH}$. Mosquito host blood meal identification: methodology and data analysis. Annu Rev Entomol. 1983;28:179-201. [PubMed] [Google Scholar]

4. Li CF, Lim TW, Han LL, Fang RA. Rainfall, abundance of Aedes aegypti and dengue infection in Selangor, Malaysia. Southeast Asian J Trop Med Public Health. 1985 Dec;16(4):560-8. [PubMed] [Google Scholar]

5. Okogun GRA, Nwoke BEB, Okera AN, Anosike JC, Esekhegbe AC. Epidemiological implications of the preferences of breeding sites of mosquito species in Midwestern Nigeria. Ann Agric Environ Med. 2003;10(2):217-22. [PubMed] [Google Scholar]

6. Perich MJ, Rocha NO, Castro AL, Alfaro AW, Platt $K B$, Solano T, Rowley WA. Evaluation of the efficacy of lambda-cyhalothrin applied by three spray application methods for emergency control of Aedes aegypti in Costa Rica. J Am Mosq Control Assoc. 2003 Mar;19(1):58-62. [PubMed] [Google Scholar]

7. Eisen L, Beaty BJ. Innovative decision support and vector control approaches to control dengue. In vectorborne diseases: understanding the environmental, human health and ecological connections. Washington, DC, USA: Workshop Summary, The National Academies Press, 2008.

8. Boreham PFL, Garrett-Jones C. Prevalence of mixed blood meals and double feeding in a malaria vector (Anopheles sacharoui) Favre. Bull World Health Organ. 1973 May;48(5):605-14. [PubMed] [Google Scholar]

9. Ponlawat A, Harrington LC. Blood feeding patterns of Aedes aegypti and Aedes albopictus in Thailand. J Med Entomol. 2005 Sep;42(5):844-9. [PubMed] [Google Scholar]

10. Agrawal SK, Ali M. Multiple blood feeding behaviour of Culex quinquesfasciatus in Marendragarh city, Chhattisgarh state, India. Glob. J. Multidiscip. Stud. 2015;4(03):23-30.

11. Kay BH, Boyd AM, Ryan PA, Hall RA. Mosquito feeding patterns and natural infection of vertebrates with Ross River and Barmah Forest viruses in Brisbane, Australia. Am J Trop Med Hyg. 2007 Mar;76(3):417-23. [PubMed] [Google Scholar]

12. Garcia-Rejon JE, Blitvich BJ, Farfan-Ale JA, Loroño-Pino MA, Chim WA, Flores-Flores LF, Rosado-Paredes E, Baak-Baak C, Perez-Mutul J, Suarez-Solis V, FernandezSalas I. Host-feeding preference of the mosquito, Culex quinquefasciatus, in Yucatan State, Mexico. J Insect Sci. 2010;10:32. [PubMed] [Google Scholar]

13. Barrera R, Amador M, Young G, Komar N. Mosquito (Diptera: Culicidae) bloodmeal sources during a period of West Nile virus transmission in Puerto Rico. J Med Entomol. 2011 May;48(3):701-4. [PubMed] [Google Scholar]

14. Gananakumar S, Arunmani M, Dwarakanath SK. Blood meal analysis of a few mosquito species in Madurai using double immunodiffusion technique. Proceedings of the second symposium on vectors and Vect. Bor. Dis. 1997, p.169-175.

15. Jauhari RK, Singh RP, Singh S. Breeding and resting site of mosquitoes in the forested areas of Doon Valley. Ind. J. Forestry. 1995;18(3):249-50.

16. Mahesh RK, Jauhari RK. Mosquito fauna of the forested areas of Doon valley, (UP) India. Entomon. 2003;28(2):185-90. 
17. Azmi SA, Das S, Chatterjee S. Seasonal prevalence and blood meal analysis of filarial vector Culex quinquefasciatus in coastal areas of Digha, West Bengal, India. J Vector Borne Dis. 2015 Sep;52(3):252-6. [PubMed] [Google Scholar]

18. Service MW. Mosquito ecology: Field sampling methods. 2nd ed. Barking, UK, Elsevier Science Publishers. 1993, p.988.

19. Ouchterlony O, Nilson LA. Immunodiffusion and immune electrophoresis. Hand Book of Experimental Immunology. Oxford: Blackwell Publishers. 1973, p.199.

20. Collins RT, Narasimham MV, Dhal KB, Mukherjee BP. Gel diffusion analysis of Anopheles blood meals from 12 malarious study villages of Orissa State, India. J Am. Mosq. Control Assoc. 1991 Dec;7(4):595-603. [PubMed] [Google Scholar]

21. Zar JH. Biostatistical analysis. 4th ed. New Delhi, India: Pearson Education (P) Ltd. (Indian Branch). 1999.

22. Sucharit $S$, Tumrasvin W, Vutikes $S$, Viraboonchai S. Interactions between larvae of Aedes aegypti and Aedes albopictus in mixed experimental populations. Southeast Asian J Trop Med Public Health. 1978 Mar;9(1):93-7. [PubMed] [Google Scholar]

23. Smith A, Weitz B. The feeding habits of Anopheles gambiae, with particular reference to subsidiary hosts. Ann Trop Med Parasitol. 1959 Dec;53:414-5. [PubMed] [Google Scholar]

24. Tandon N, Ray S. Host feeding pattern of Aedes aegypti and Aedes albopictus in Kolkata India. Deng. Bull. 2000;24:117-20. [Google Scholar]

25. Scott TW, Clark GG, Lorenz LH, Amerasinghe PH, Reiter $\mathrm{P}$, Edman JD. Detection of multiple blood feeding in Aedes aegypti (Diptera: Culicidae) during a single gonotrophic cycle using a histologic technique. J Med Entomol. 1993 Jan;30(1):94-9. [PubMed] [Google Scholar] 